\title{
ESTUDIOS
}

\section{Borges y Paz: Un Diálogo de Textos Críticos}

.. ese mundo de ideas que, al desplegarse, crea un espacio intelectual: el ámbito de una obra, la resonancia que la prolonga $o$ la contradice. Ese espacio es el lugar de encuentro con las otras obras, la posibilidad del diálogo entre ellas.

Octavio PAz: Corriente altema (1967)

Pocos nombres hay más tantalizadores en la cultura contemporánea que los de Jorge Luis Borges y Octavio Paz. Tanto el pocta argentino como el mexicano han trascendido hace algunos años los límites algo parroquiales, de sus respectivos ámbitos y han proyectado su obra hacia América (latina, o no), hacia el Occidente europeo. Mencionar hoy en un contexto internacional a Borges o a Paz, es hablar de quienes supieron demostrar aquella intuición con la que se cierra El laberinta de la soledad: hoy los latinoamericanos somos "por primera vez en nuestra historia, contemporáneos de todos los hombres". ${ }^{1}$ La frecuencia con que se cita, o alude, en textos franceses o norteamericanos, ingleses o alemanes, a la obra de. Borges o a la de Paz, es prueba suficiente de esa "contemporaneidad", tan difícilmente alcanzada por una cultura que, hasta hace muy poco, había sido considerada marginal, periférica, meramente repetitiva. Hoy lo que dice Borges sobre Henry James o sobre Kafka (y no sólo lo que dice sobre Lugones o Carriego) se examina con atención en Occidente; lo que Paz dice sobre Lévi-Strauss o sobre el tantrismo encuentra réplica en los medios especializados. De alguna manera, los nombres de Paz y de Borges se han convertido en cifra (o símbolo) de un

1 Octavio Paz, El laberinto de la soledad (México, Cuadernos Americanos, 1950), p. 192. 
modo de ser y de leer de la cultura contemporánea. Descodificarlos es tarea de toda persona culta, no importa cuál sea su origen. Tanto Paz como Borges han logrado en nuestros días lo que resultó imposible para Bello y Sarmiento, para Machado de Assis y Euclides da Cunha, para Da_ río y Rodó, para Reyes y Mariátegui: atraer la atención de un auditorio verdaderamente internacional que dedique a sus textos el mismo cuidado que a los de sus contempotáneos europeos o norteamericanos, que los descifre sin condescendencia, sin prisas, sin anacronismo.

En el contexto de la cultura hispanoamericana actual, los nombres de Borges y Paz adquieren, aún, mayor relieve. En más de un sentido ellos polarizan ciertos rasgos que deben ser tenidos en cuenta antes de proceder a un análisis más pormenorizado de sus respectivas figuras. Los une cierta común actitud intelectual ante el fenómeno estético: actitud que no supone (es claro) una idéntica solución de los problemas. Tanto Paz como Borges no desdeñan la práctica cotidiana de la inteligencia y de la erudición. Poetas cultos aún en sus momentos de arrebato o pesadilla, la inteligencia lúcida, la iluminación intelectual es constante de sus respectivas obras, y sostiene una meditación crítica, profundamente personal. Ni Borges ni Paz han renegado nunca de su condición de intelectuales: saben que el poeta no tiene (no puede tener) una actitud de ignorancia frente a los problemas del lenguaje, frente a los fenómenos estéticos, frente a las especulaciones retóricas. Poetas y críticos, a la vez, tanto Borges como Paz han analizado la obra ajena casi tanto como la propia; han sometido el fenómeno (al cabo inexplicable) de la creación poética a un escrutinio infatigable.

Decir esto no significa afirmar, como fingen creer algunos, que Paz - Borges desconocen o desdeñan las otras facultades sin las cuales la creación poética o crítica es imposible. La obra lírica de Paz parte de la lucidez para llegar al deslumbramiento del éxtasis; la de Borges utiliza la inteligencia para socavar $y$, en definitiva, destruir su propia arrogancia. La intuición avasalladora, el chispazo eléctrico que salta entre dos polos lejanísimos, la capacidad de cortar al sesgo en las distintas napas de la realidad, son otras tantas caracteristicas de la obra crítica respectiva de Paz y de Borges. Pero si la inteligencia de ambos no funciona en el vacío, también es cierto que ella es el medio conductor de esa carga poética o crítica que contiene la obra de ambos.

También los une la aceptación deliberada, consciente, programática, de una tradición cultural que nos llega de Occidente y que transforma nuestro quehacer literario en la renovada construcción y destrucción del diálogo iniciado hace siglos a orillas del Mediterráneo. En ambos, el 
americanismo no excluye sino incorpora esa tradición mediterránea. Demasiado lúcidos para ignorar que utilizan un instrumento verbal europeo, ambos miran la realidad de sus respectivas Américas con la disciplina que han aprendido en vastas bibliotecas de volúmenes poliglotos. Su americanismo es abierto. Abierto a la realidad lingüística múltiple de esa tradición mediterránea a la que se incorpora naturalmente el mundo anglosajón, y más recientemente, el mundo eslavo. Pero también abierto a la mudable realidad circunstancial de Argentina y México. Por eso, tanto Borges como Paz han podido dejar (por ejemplo) amonedada una imagen del machismo latinoamericano en "Hombre de la esquina rosada" - El laberinto de la soledad, o han sabido explorar en obras más poéticas (Fervar de Buenos Aires, ¿Aguila o Sol?) las cifras primeras y ocultas de sus respectivas realidades.

Su americanismo está, también, abierto a otras tradiciones no mediterráneas. Tanto para Borges como para Octavio Paz el Oriente es, asimis_ mo, parte de esa tradición cultural abarcadora que tiene su centro en el Meditertáneo: Porque no hay que olvidar que ambos descodifican la cultura oriental a partir de libros europeos. Borges descubre el Oriente en una biblioteca de sinología que estaba en Ginebra y ahora está en Montevideo. Paz empieza a leer el Oriente en libros obtenidos en Francia. Es cierto que, más tarde, visitará el Oriente e, incluso, llegará a residir en la India durante seis años, como embajador de su patria, en tanto que el Oriente de Borges es (aún hoy) el de las Mil y una nocbes leídas en la biblioteca paterna, el Oriente de Kipling y del capitán Burton, de enciclopedias chinas apócrifas, de no menos apócrifas historias. de viudas dedicadas a la piratería en el vasto Mar Amarillo. Pero la circunstancia de que Paz haya echado raíces en la tierra cultural de la India y pueda escribir con la autoridad de la experiencia directa, no altera el hecho fundamental de que su descodificación del Oriente es, también, de raíz meditertánea. Y no puede ser de otro modo. Porque él es un poeta para quien el Oriente ha sido, sobre todo, una experiencia interior: la prueba de fuego para el fénix, el renacimiento de un Paz más auténtico que nunca de las cenizas de otros avatares. Pero ésta es ya otra historia.

\section{II}

No conviene, sin embargo, exagerar el paralelismo entre Borges $y$ Paz. Muchas cosas los separan, y en forma abismal. Aquí sólo trataré de considerar la que separa la obra crítica de uno de la del otro. 
No sólo la distancia cronológica de quince años (Borges es de 1899, $\mathrm{Paz}$ de 1914), con lo que ella supone de distancia generacional, los distingue considerablemente. Un solo ejemplo: la revolución rusa de 1917 encuentra a Borges con el fervor intacto de los dieciocho años; escribirá un poema expresionista dedicado a la roja aurora de Moscú; pero su entusiasmo pronto dará lugar al desengaño y a un anticomunismo de perfil maniqueísta, casi inconcebible en un hombre tan sutil en otros campos. Para Paz, la revolución rusa es un hecho histótico (tiene tres años cuando ocurre) y será la lucha entre Stalin y 'Trotzky lo que despierte su conciencia política y marque, desde entonces, su compromiso con el mundo. En tanto que la desilusión del totalitarismo soviético lleva a Borges al anticomunismo, la crítica trotzquista servirá a Paz de estímulo para una exploración, cada vez más original, de la naturaleza del universo político.

Tampoco es negligible la distancia histórica de las respectivas culturas mexicana y argentina. En tanto que México tiene muy hondas raíces en -1 pasado pre-colombino, Argentina levanta su cultura sobre un suelo indígena escaso, casi desértico, pero generosamente abonado por oleadas de inmigrantes mediterráneos. Borges sólo puede ser un americano-europeo; Paz es, además, un americano indígena. Por otra parte, la geopolítica, que determina la forzada vecindad de México con los Estados Unidos, ha contribuido al desarrollo de un poderoso nacionalismo en la nación azte. ca, nacionalismo que Paz ha analizado (en su luz y en su sombra) tan magistralmente en El laberinto de la soledad y en Posdata. Para Borges, en cambio, el nacionalismo o es sólo un anactónico concepto romántico, o es una experiencia de la sangre encarnada por la teoría de militares de su familia que ayudaron a hacer la patria. En su actitud frente a los Estados Unidos, Borges refleja esa distancia geográfica entre Argentina y la poderosa nación del Norte; pero refleja también una incapacidad de asumir un destino continental que se proyecte más allá de la gesta de Junín o Ayacucho, y lo comprometa a él, personalmente.

Estas diferencias no son, sin embargo, puramente individuales. En mayor o menor medida, son diferencias que reflejarían también otros mexicanos y argentinos de la misma situación generacional. Las diferencias y distancias más importantes, a mi juicio, son las establecidas por el destino particular de ambos escritores. En Borges se ofrece la imagen (pluscuamperfecta, como ha escrito él del Monsieur Teste, de Valéry) del escritor cuya vida se alimenta sólo de libros. El mismo lo ha dicho y repretido mil veces. Una de las veces, en el "Epílogo" de El bacedor (1960): 
Pocas cosas me han ocurrido y muchas he leido. Mejor dicho: pocas cosas me han ocurrido más dignas de memoria que el pensamiento de Schopenhauer o la música verbal de Inglaterra. ${ }^{2}$

Paz, en cambio, es un escritor en que la actividad intelectual está siempre situada en un contexto social más amplio y variado. Como Borges, ninguna pasión le es ajena, pero en tanto el escritor argentino vive sus pasiones pecho adentro y rara vez las expresa en la mera realidad (como él mismo diría), Paz es un hombre que vive lo que sueña; o, mejor dicho, lo vive dos veces: en el sueño de la realidad y en el sueño de la escritura. Por eso no le ha faltado nunca, ni le falta hoy a Paz, el compromiso político y humano. Desde su participación en la guerra civil española hasta su reciente intervención en el debate político mexicano (debate al que las valientes páginas de su Posdata han dado un contexto hondísimo, casi abismal), Octavio $\mathrm{Paz}$ ha sabido "suit the action to the word, the word to the action", como decía el principe Hamlet en otro contexto. En Borges, la protesta, o la participación política (que no falta, aunque a veces sea lamentable), es siempre verbal. Con muy escasa vista desde la adolescencia, sometido en el curso de su juventud a no menos de seis operaciones hasta quedar prácticamente ciego en el umbral de la vejez, Borges vive una realidad en que todo es sombras, o reflejos de sombras, sobre los muros de una caverna de palabras.

Si se deja la circunstancia biográfica para examinar la circunstancia cultural específica de sus respectivos destinos, las distancias entre Borges y Paz continúan ahondándose. La influencia de una abuela inglesa, que le enseña a leer en la lengua de Dickens antes que en la de Galdós; el modelo tutelar de un padre, profesor de psicología en un colegio inglés de Buenos Aires, marcan desde el comienzo a Borges (o Georgie, como lo llaman en casa) con el sello de una cultura anglosajona que reitera a la distancia los moldes de una cultura imperial. La Argentina de la clase alta, por otra parte, estará más orientada hacia Inglaterra que hacia Francia. Borges irá a educarse en Europa pero no será en París donde haga su bachillerato sino en Ginebra, y allí aprenderá no sólo el francés sino el alemán, profundizando y diversificando así su conocimiento de las raíces de esa cultura anglosajona que es suya por herencia de sangre. Mucho más tarde, como profesor de literatura inglesa y norteamericana en la Facultad de Filosofía y Letras de la Universidad de Buenos Aires, Borges se internará en los territorios mágicos de la primitiva poesía anglosajona para desembocar recientemente (era inevitable) en los aún

2 Jorge Luis Borges, El bacedor (Buenos Aires, Emecé Editores, 1960), p. 109. 
más remotos y espléndidos monumentos de la cultura escandinava. Hoy, Islandia, lo atrae con la fascinación de una tierra distante, secreta, inaccesible. Todo lo que es español, y por lo tanto obvio, en la cultura tioplatense; todo lo italiano, que ha enriquecido tanto la letra y la música de esa zona del Plata, es ajeno a Borges, o le resulta hostil. Leyó por primera vez el Quijote en inglés, y aunque ha dedicado páginas muy sutiles a Cervantes, sus autores siguen siendo De Quincey o Stevenson, Browning o Chesterton, Swinburne o Kipling, Poe o James, Emerson o Whitman, Mark Twain o Faulkner, Schopenhauer o Kafka. Ël, que ha escrito tanto y tan bueno sobre La Divina Comedia, sobre Ariosto, sobre Croce, asegura no entender una palabra de las películas italianas y deplora la influencia de los inmigrantes itálicos en el sentimentalismo de las letras de tango.

Octavio Paz, por el contrario, empieza por asumir muy conscientemente las raíces hispánicas: lo que en México es señal de independencia. No sólo va a España en la hora de agonía de 1937, sino que toda su poesía primera y su obra crítica arrancan de una lectura muy personal de algunas grandes voces de la España contemporánea. Unamuno y Machado guían con su obra al joven Paz, y la huella de ambos es muy visible en todos sus escritos de iniciación, hasta $E l$ arco y la lira, por lo menos. Otro español, José Bergamín, influitá también en el joven: Su presencia en México durante los años que siguen a la guerra civil española servirá de agente catalítico. El habrá de estimular en Paz a una lectura más imaginativa de la literatura española, de los románticos alemanes, de Lautréamont y los surrealistas, de Heidegger. La otra gran fuente europea de su obra es esa literatura francesa a la que vuelve incesantemente, como punto de referencia, su meditación crítica. Aquí se funda una de las grandes diferencias con Borges. Porque si bien el escritor argentino se nutrió en su juventud de Mallarmé y Valéry, Flaubert y Apollinaire, Maupassant y Henri Barbusse, Marcel Schwob y Remy de Gourment, su descodificación de la cultura francesa es demasiado heterodoxa, demasiado personal y arbitraria, para poder compararse con la ordenada, sistemática, ávida lectura que practica Paz desde los años cuarenta, por lo menos. No se trata sólo de que él esté siempre al día y lea en 1945 a Sartre y a Camus, como a Robbe-Grillet y Lévi-Strauss en 1965. Ni se trata tampoco de que la experiencia viva y literaria de André Breton haya marcado honda. mente su meditación crítica desde los años en que frecuentó al maestro del surrealismo en México, o en su propio habitat parisino. (En Borges sólo Macedonio Fernández, el heterodoxo Sócrates porteño, ha tenido similar influencia; pero Macedonio era lo contrario de un Breton; era 
un maestro sin discípulos ni capilla, sin obra visible, sin estrategia poética alguna.)

Por eso, cuando se piensa en Borges, se piensa en un escritor que es parcialmente inexplicable si no se conoce el contexto de cultura anglosajona en que se inscribe su obra entera. Con Paz, es el contexto de la cultura francesa, o a la francesa, el que resulta imprescindible. Porque incluso lo que no es cultura francesa llega a Paz a través de Francia: será en Albert Beguin donde Paz descubra a los románticos alemanes, como será a través del estructuralismo francés que Paz se abra camino hasta la obra del lingüista ruso-norteamericano Roman Jakobson. El que Paz y Borges aparezcan como respectivos tributarios de dos de las más ricas corrientes de la cultura actual, acentúa aún más sus diferencias individuales. Porque la rivalidad entre el mundo anglosajón y el francés (rivalidad que sólo puede entenderse en el contexto parroquial de la Europa de fines de la Edad Media pero que carece de todo sentido hoy) ha impedido que las increíbles invenciones, de ambas culturas se integren armoniosamente en la misma Europa. Una de las raíces de la incomprensión recíproca que podría revelar un diálogo entre textos de Borges y textos de Paz se encuentra, indudablemente, aquí.

Conviene advertir, antes de continuar más adelante, que si afirmo que tanto Borges como Paz son tributarios de esas corrientes paralelas, no intento con ello disminuir en nada su respectiva originalidad, ni (cosa aún menos tolerable) la profundidad de su entronque con las culturas nacionales a las que sus obras pertenecen. Sólo un concepto muy analfabeto de la literatura, o de la cultura, permite creer que las influencias extranjeras son nefastas o deben extirparse drásticamente. Quienes sostienen hoy esta teoría entre nosotros (y son bastantes, por desgracia) parecen ignorar que ya fue postulada en la Roma imperial y que contra ella debió escribir Horacio su Epistola a los Pisones. Pero la xenofobia de algunos de nuestros compatrictas de continente les impide reconocer el origen extranjero de esas mismas doctrinas nacionalistas que profesan, con tanto ardor e ignorancia.

Tanto Borges como Paz se han visto atacados por tratar en sus libros asuntos extranjeros, o por reformular teorías extranjeras. El nivel en que, por lo general, se sitúan esos ataques es casi inverosímil. Hacia 1954, un profesor argentino que hoy goza de cierta reputación en su patria, escribió un panfleto en que denunciaba el extranjerismo de Borges, apoyándose en una lectura muy literal de algunos conceptos de sociología literatia emitidos por Lucien Goldmann (un rumano) y Jean-Paul Sartre 
(un francés). ${ }^{3}$ En una reciente reseña de Configurations, el último libro de Paz traducido al inglés, un poeta norteamericano de cuyo nombre prefiero no acordarme pone en duda las credenciales de Paz para escribir sobre el Oriente, o sobre temas orientales, por considerar!o un "turista", a pesar de que ha vivido seis años en la India. ¿Se le habría ocurrido al benemérito reseñador preguntarle a Ezra Pound cuántos años vivió en Chino, o en la Provenza de los trovadores? Pero no nos perdamos. Conviene repasar ahora el texto de una conferencia con la que Borges respondió a algunos de estos nacionalistas de pacotilla. Es un texto de 1951 que está incorporado al volumen titulado Discusión, el sexto de sus Obras Completas. Copio algunos párrafos:

.. no sé si es necesario decir que la idea de que una literatura debe definirse por los rasgos diferenciales del país que la produce es una idea relativamente nueva; también es nueva y arbitraria la idea de que los escritores deben buscar temas de sus países. Sin ir más lejos, creo que Racine ni siquiera hubiera entendido a una persona que le hubiese negado su derecho al título de poeta francés por haber buscado temas griegos y latinos. Creo que Shakespeare se habría asombrado si hubieran pretendido limitarlo a temas ingleses, y si le hubiesen dicho que, como inglés, no tenía derecho a escribir Hamlet, de tema escandinavo, o Macbeth, de tema escocés. El culto argentino del color local es un reciente culto europeo que los nacionalistas deberían rechazar por foráneo. (...)

Quiero señalar otra contradicción: los nacionalistas simulan venerar las capacidades de la mente argentina pero quieren limitar el ejercicio poético de esa mente a algunos pobres temas locales, como si los argentinos sólo pudiéramos hablar de orillas y estancias y no del universo. (...)

Por eso repito que no debemos temer y que debemos pensar que nuestro patrimonio es el universo; ensayar todos los temas, ya que no podemos concretarnos a lo argentino para ser argentinos: porque o ser argentino es una fatalidad y en ese caso lo seremos de cualquier modo, o ser argentino es una mera afectación, una máscara.

Creo que si nos abandonamos a ese sueño voluntario que se

3 Adolfo Prieto, Borges y la nueva generación. Buenos Aires, Letras Universitarias, 1954.

4 Robert Bly, "Configurations", in The New York Times Book Review, April 18,1971 , pp. 6,20 y 22 . 
Ilama la creación artística, seremos argentinos y seremos, también, buenos o tolerables escritores. ${ }^{5}$

Sería fácil encontrar en los textos críticos de Paz puntos de vista semejantes. Tanto en Borges como en $\mathrm{Paz}$ esa tradición, originariamente mediterránea, pero ahora atlántica y americana, está polémicamente viva.

\section{III}

En cierto sentido, Borges y Paz renuevan en nuestros días el diálogo que (en la mera realidad, o en la confrontación imaginaria de sus textos) mantuvieron en otras épocas de nuestra cultura, Bello y Sarmiento, Darío y Rodó, Alfonso Reyes y Mariátegui. Es un diálogo hecho de coincidencias aparentes $y$ hondas discrepancias, de voces que atraviesan tierras y mares para decir las mismas cosas de manera muy distinta, o cosas diametralmente opuestas de un modo similar. Es (a veces) un diálogo vivo en que una suerte de síntesis armoniosa ocurre al final. Pero es (también) un diálogo de sordos; a el combate de diligentes duelistas en una niebla de palabras. Escuchar sus voces conjuntas y discrepantes, reconocer ecos y resonancias, descifrar una profunda, inevitable, oposición, es estar sometido a la más tantalizadora de las operaciones de la lectura: el palimpsesto creado por la imaginación del lector, la sabreimpresión fotográfica en una retina que todavía conserva la imagen del texto anterior, la cinta de la memoria en que se vuelve a grabar sobre lo grabado.

Soy lector devotísimo de Borges casi desde mis orígenes literarios. Lo descubrí, por azar, por destino tal vez, cuando tenía unos quince años, leyendo una revista femenina, El Hogar, de Buenos Aires, a que estaba suscripta mi tía, y en la que Borges redactaba quincenalmente una eruditísima sección de "Libros y Autores Extranjeros". Desde entonces, la lectura de Borges ha sido mi profesión. Leer a Paz después de haber leído a Borges; descubrir a Paz después de haber descubierto a Borges, ha sido para mí una experiencia de frustración y deslumbramiento, de disciplina y confusión, de raro suplicia de Tántalo. Paz empezó a existir para mí a partir de El Hijo Pródigo, una de las revistas fundacionales de la nueva literatura hispánica. La lectura, a comienzos de los años 50, de El laberinto die la soledad, no hizo sino confirmar lo que había encontrado en los textos de aquella revista. Después vino El arco y la lire ¿A qué seguir? Todo Paz estaba ya implícito en los primeros textos.

5 Jorge Luis Borges, Discusión (Buenos Aires, Emecé Editores, 1957), pp. $155-56,158,162$, respectivamente. 
Pero insisto, leer a Paz después de haber descodificado a Borges, o volver a Borges después de haber recorrido a $\mathrm{Paz}$, es una experiencia singularmente tantalizadora. ¿Cuántas veces no he lamentado, por ejemplo, que Paz no desatrollase un poco más cierta hipótesis de El arro y la lira sobre la novela moderna a la luz de lo que Borges había escrito, quince años antes, en el prólogo a La invención de Morel? Pero Paz no parece haber prestado atención entonces a ese prólogo, a a la extraordinaria novela de Bioy Casares, a esa misma que años más tarde celebraría RobbeGrillet en un ensayo crítico, y en el libreto cinematográfico de L'arnée dernière à Marienbad. ¿Cuántas veces, asimismo no lamenté que Paz no castigase su tendencia a descansar tanto en la bibliografía francesa, embarcándose en una exploración de primera mano de la inesperada bibliografía en inglés que Borges maneja con tanta familiaridad como displicencia erudita? Pero también: ¿cuántas veces, al volver a Borges después de una deslumbrante excursión por las páginas de Paz, no he lamentado que la inconexa y caprichosa erudición del maestro argentino le impidiera muchas veces redondear su argumento con la precisión del mexicano? ¿Cuántas veces, después de seguir a Paz en sus lecturas de Heidegger o Lévi-Strauss, no he sentido que Borges se haya quedado (como petrificado mágicamente) en los libros de su juventud, o de la madurez de su padre, ese don Jorge Borges que ha proyectado una sombra intelectual tan larga sobre la obra de su hijo, su alter ego, su creación, su Golem? Leer a Borges y, luego, leer a Paz; leer a Paz y volver a Borges, ha sido para mí un ejercicio de secreta desesperación pero también un ejercicio de infinito aprendizaje. Algún día habré de intentar (con el espacio y el tiempo que aquí me faltan) un examen paralelo de la obra crítica de ambos: examen que incluya, naturalmente, la obra poética respectiva, ya que en ambos la poesía y la crítica no se oponen sino que se integran en una unidad superior. Ahora, como anticipo de ese estudio, intentaré subrayar solamente algunos aspectos centrales de ese diálogo de textos críticos. Diảlogo que no ha ocurrido nunca en la mera realidad y que, sin embargo, en el espacio imaginario de mi lectura no ha cesado, ni cesa, de ocurrir.

\section{IV}

Tal vez la forma más inmediata de acceder por ahora a ese diálogo imaginario sea a partir de la obra crítica de Paz: obra que se desartolla en forma aparentemente más coherente y sostenida que la de Borges. Suman ya una docena los libros de crítica publicados por el escritor 
mexicano en las últimas dos décadas. A partir de El laberinto de la soledad (1950), El arco y la lira (1956) y Las peras del olmo (1957), Paz desarrolla en la década siguiente y hasta nuestros días, una obra de corrección y ampliación de los textos básicos que contienen esos volúmenes. $E l$ laberinto de la soliedad, meditación sobre el ser mexicano ( $y$, hasta cierto punto, latinoamericano), encuentra una incisiva Posdata en 1970, escrita a partir de la matanza de Tlatelolco y centrada en una interpretación simbólica del significado ritual del sacrificio aparentemente inexplicable de vidas que ocurrió ese día trágico de 1968. El arcio y la lira se prolonga en 1965 en un ensayo, Los signos en rotación, que habrá de incorporarse como epílogo a la segunda edición de aquella obra: segunda edición que once años después de la primera rectifica, explícita o tácitamente, muchas de sus premisas originales. Las peras del olmo inaugura una serie de coleciones de artículos misceláneos que en 1966 se aumentará con Puertas al campo $\mathrm{y}$, en 1967, con Corriente alterna, el más importante hasta ahora. Un nuevo tipo de enfoque crítico se inicia con la publicación, en 1965, de Cuadrivio. Allí explora Paz la obra de cuatro poetas y define en torno de ella ana meditación sobre la poesía. Dario, López Velarde, Fernando Pessoa, y Luis Cernuda son los puntos de partida, o pretextos, en aquel libro. En el prólogo a una antología, Poesia en movimiento, Méxicio, 1915-1966, es la evolución de un género en un contexto literario muy preciso lo que suscita el más deslumbrante y polémico ejercicio combinatorio. En otra variante del mismo tipo de enfoque, son las teorías de un famoso antropólogo francés las que sirven de punto de arranque a Clande Lévi-Strauss o el nuevo festin de Esopo (1967). La relectura (muy personal) que hace Paz del maestro del estructuralismo habrá de encontrar más apropiado espacio en su último libro de ensayos: Conjunciones y disyunciones (1970). Allí, la picardía mexicana, las interpretaciones de Freud y Norman Brown sobre el aspecto excremental de la economía y su vinculación profunda con la psicología anal, se unen a deslumbrantes visiones del tantrismo búdico para sostener una teoría del amor, el erotismo y el sexo en que Paz vuelve críticamente sobre preocupaciones que su poesía última ha capturado con singular energía. ${ }^{6}$

En esta docena de volúmenes, el gran poeta mexicano ha desarrollado una obra crítica que si bien no compite con su creación poética reclama un examen particular. Es una obra que ilustra perfectamente lo que T. S. Eliot ha definido como la crítica de los practicantes; es decir: la crítica

6 He desartollado el tema de este capítulo en un artículo: "Octavio Paz: Critica y Poesía", in Mundol Nuevo, No. 21, París, marzo 1958, pp. 55-62. Aquí aprovecho algunos párrafos de dicho estudio. 
hecha por el creador, que sirve no sólo para ilustrar a los lectores (función primordial de la crítica a secas) sino para iluminar también al creador sobre los caminos secretos de su propia obra. A esa crítica de practicantes (tan antigua como la Epistola a los Pisches, de Horacio), algunos poetas modernos han contribuido páginas perdurables. No es mecesario levantar aquí un inventario completo. Baste recordar que, desde Coleridge al mismo Eliot, de Poe a Ezra Pound, de Baudelaire a Breton, de Novalis a Rilke, la crítica moderna es, en gran medida, una discusión de lo que los practicantes han dicho sobre la poesía, propia o ajena. En América Latina no han faltado, desde Bello, el fundador, notables practicantes: Martí, Darío, Rodó, Alfonso Reyes, Borges, son tal vez los más ilustres precursores de Octavio Paz.

Un tema común, superficial pero importante, corre a través de la meditación crítica de Paz: es el tema de la insuficiencia de la crítica literaria en lengua española. Ya en El arco y la lira había planteado el problema en sus términos más generales.

Cuando se dice que en español no hay crítica, debe pensarse sobre todo on la ausencia de esa prosa de alta calidad intelectual que equilibra la balanza del idioma. Pues así como la prosa nació de la poesía, así también la poesía moderna necesita de la proximidad de la prosa. Hay una continua comunicación entre ambos mundos. (Un ejemplo de lo que quiero decir es la obra de Alfonso Reyes; pero una golondrina no hace verano.) La función de la prosa crítica no consiste tanto en juzgar las obras poéticas -- tarea vana entre todas- como en hacer posible su plena realización. $Y$ esto de dos maneras: a través de un constante cultivo y nivelación del suelo idiomático, como el labriego que prepara la tierra para que la semilla fructifique; y después, acercando la obra al oyente. El crítico debe facilitar la comunión poética - sin la cual el poema no es sino ociosa posibilidad - y luego retirarse. Todo se opone entre nosotros a esta doble misión de la crítica. Por una parte, la envidia es un mal, mucho más profundo de lo que se cree, que corroe a todos los pueblos hispánicos. Por la otra, la prosa española es en sí misma excepcional y única, universo cerrado, creación que rivaliza con el poema. La prosa no sirve a la poesía porque ella misma tiende a ser paesía. Unamuno y Machado son buenos ejemplos de lo que quiero decir. ${ }^{7}$

7 Octavio Paz, El arco y la lira (México, Fondo de Cultura Económica, 1956), p. 84 . 
Conviene advertir, antes de seguir adelante, que al teeditar $E l$ arco y la lira en 1967, Paz suprime esta larga tirada. Es fácil comprender por qué elimina este párrafo de la segunda edición. Si ya en 1956 era excesivo afirmar que no había crítica en español (él mismo señalaba la excepción de Alfonso Reyes, pero omitía mencionar otras: Borges, Amado Alonso, Martínez Estrada, para citar sólo a tres), en 1967 la misma frase era insostenible. Por lo menos en estos términos absolutos. De ahí la supresión del párrafo entero. ${ }^{8}$ En 1967, Paz ve a la crítica como algo distinto que como un servicio poético. El humilde labriego de su símil resulta doblemente anacrónico ya que el crítico hace algo más que preparar el terreno y acercar la obra al lector. Su obra es paralela a la del creador, y no simplemente introductoria. Pero lo que me interesa subrayar ahora en aquella toma de posición de 1956 no es la exactitud de una generalización tal vez demasiado imbuida de la naturaleza "divina" de la creación poética, sino la verdad fundamental que contiene, al margen de su amplifi. cación retórica. No había entonces en el ámbitor del idioma español, o por lo menos no la había en cantidad suficiente, una crítica de alta calidad intelectual. Es indudable que Octavio $\mathrm{Paz}$, que entonces reside en Francia, está aludiendo precisamente a ese subsuelo teórico y analítico que constituye la prosa crítica en la muy intelectualizada literatura francesa de este siglo. Pero lo mismo podría haber escrito en un contexto inglés, o norteamericano, alemán o italiano.

La observación de 1956 encuentra su desarrollo en trabajos posteriores, en comentarios marginales, en alusiones y hasta malhumores que asoman en casi todos los textos de la última época. Hay un largo onsayo de Puertas al campo que contiene valiosas referencias indirectas a este tema central de las letras hispanoamericanas. "El precio y la significación" es su título que alude precisamente a una de las confusiones más celebradas de la crítica: confundir el valor de una cbra de arte con su precio. Allí hay una frase que, como muchas de Paz, tiene la precisión y vigor de su mejor poesía. Al referirse a uno de los pocos críticos de poesía que hay en México, Paz señala que es "algo insólito en un medio que confunde la crítica con la reseña periodística o con la dentellada de perro rabioso". 9 En otra página del mismo libro, apunta y confirma:

Lo que se llama la "república de las letras" no existe entre nosotros. No sé si es un bien o un mal. Existen en cambio los caudillos y lás

8 Véase mi artículo: "Relectura de El arco y la lira", in Revista Iberoamericana, No. 74, Pittsburgh, enero-marzo, 1971 p. 35-46, para una discusión más detallada de ésta y otras supresiones.

9 Octavio Paz, Puertas al campo (México, UNAM, 1966), p. 272. 
bandas. Oscilamos entre la promiscuidad de la horda y la soledad de los anacoretas. Literatura de robinsones, polifemos y ermitaños. Cada uno en su isla, en su cueva o en su columna. Unos armados hasta los dientes, son el terror de la comarca; otros, inermes y semidesnudos y a pan y agua, viven como don Quijote cuando hacía penitencia en Sierta Morena. ${ }^{10}$

Lo que aquí dice Paz de su México, no es sólo válido para dicho país. Êl mismo se encarga de generalizar en otro artículo del mismo libro.

En Hispanoamérica, además, ya sea por timidez, cobardía, asco o desdén, desde hace mucho los escritores han abandonado el ejercicio de la crítica, que ha caído en manos de periodistas, cronistas de radio y televisión, agentes de publicidad y censores morales y religioscs. El arte ya forma parte de la actualidad; y son los criterios de la actualidad —el comercio y la política, es decir: la compraventa y la propaganda- los que sirven para juzgarlo. Una obra es buena si se vende o si su "mensaje" ayuda a mi partido. La "sensación" y la "utilidad" son los dos valores supremos de la crítica contemporánea. ${ }^{11}$

Que este tipo de "crítica" no está sólo reservada a los mercaderes del arte, lo indica asimismo una anotación sobre el estado del arte mexicano de los años 40 que figura on el mismo libro:

En México, entre 1940 y 1950 aproximadamente, atravesamos por un período vacío. Desaparecidas las grandes revistas (la última fue El Hijo Pródigo), silenciosa la generación de Contemporáneos -isla de lucidez en un mar de confusiones-, la crítica oscilante entre el vituperio y el incienso, sólo dos o tres voces, en la poesía y en la pintura, se opusieron al nacionalismo y al sistema. La moda era "progresista" y se condenaba al disidente con el "ninguneo". ${ }^{12}$

Esta última institución que Paz menciona, y que también suele llamarse, "conspiración de silencio", o (más patéticamente) "muerte civil", es el recurso favorito en América Latina para obliterar una obra que molesta por su propia importancia. Que no está reservada exclusivamente

10 Cf. "Un ermitaño: Cristóbal Serra", in Puertas al campo, p. 140.

11 Cf. "Marco Antonio Montes de Oca", in Puertas al campo, pp. 122-23.

12 Cf. "El precio y la significación", in Puertas al campo, pp. 271-72. 
a la derecha (como afirman piadosamente algunos) es algo que los últimos diez años de política cultural revolucionaria ha demostrado anpliamente, y para hartazgo de todos.

No es, sin embargo, en Puertas al campo (tal vez el libro misceláneo menos interesante de Paz) donde se encuentta el análisis más completo de este problema vital para la cultura latinoamericana de hoy. Un texto que recoge Corriente alterna y que lleva el título, explícito, de "Sobre la crítica", apunta que es éste el "punto flaco" de la literatura hispanoamericana. Aunque no ignora que hay buenos críticos, y hasta menciona generosamente a cuatro, su observación se refiere a la crítica como conjunto.

Carecemos de un "cuerpo de doctrina" o doctrinas, es decir, de ese mundo de ideas que, al desplegarse, crea un espacio intelectual: el ámbito de una obra, la resonancia que la prolonga o la contradice. Ese espacio es el lugar de encuentro con las otras obras, la posibilidad del diálogo entre ellas. La crítica es lo que constituye eso que llamamos una literatura y que no es tanto la suma de las obras como el sistema de sus relaciones: un campo de afinidades y oposiciones. ${ }^{13}$

Como se ve, regresa aquí Paz al punto de vista ya indicado en $E l$ arco y la lira, pero ahora lo hace para desarrollar lo que en aquella obra era sólo un comentario marginal, no suficientemente meditado. En el nuevo texto, después de indicar esa necesaria simbiosis entre crítica y creación, y de ilustrar el valor "creador" de la crítica con ejemplos que van (mutatis mutandis) de Dante a Cortázar, pasando por Góngora, Leopardi, Baudelaire, Kafka, Breton, Pessoa y Borges, el poeta mexicano apunta que:

Si se pasa de la crítica como creación a la crítica como alimento intelectual, la escasez se vuelve pobreza. El pensamiento de la época - las ideas, las teotías, las dudas, las hipótesis- está fuera y escrito en otras lenguas. Salvo en esos raros momentos que se llaman Miguel de Unamuno y Ortega y Gasset, todavía somos parásitos de Europa. Por último, si se pasa a la crítica literaria propiamente dicha, la pobreza se convierte en miserias. Ese espacio al que me he referido y que es el resultado de la acción crítica, lugar de unión y de confrontación de las obras, entre nosotros es un no man's land. La misión de la crítica, claro está, no es inventar obras sino ponerlas

13 Octavio Paz, Corriente alterna (México, Siglo XXI, 1967), pp. 39-40. 
en relación: disponerlas, descubrir su posición dentro del conjunto y de acuerdo con las predisposiciones y tendencias de cada una. En este sentido, la crítica tiene una función creadora: inventa una literatura (una perspectiva, un orden) a partir de las obras. Esto es lo que no ha hecho nuestra crítica. Por tal razón no hay una literatura hispanoamericana aunque existe ya un conjunto de obras importantes. ${ }^{14}$

Un observador marxista indicaría que la ausencia de la crítica es resultado del subdesarrollo de la cultura latinoamericana. Por ser la crítica una función eminentemente social (ese espacio al que se refiere Paz es el espacio cultural de la sociedad), es la más afectada por la pobreza y limitación de recursos de la literatura latinoamericana. La famosa incomunicación entre las distintas naciones, la obsesión y fijeza con que se mira a Europa (principalmente a Francia), la inexistencia de revistas de crítica que realmonte circulen y funden opinión en todo el continente, son otras tantas manifestaciones de ese subdesarrollo. No es casual, por ejemplo, que algunos de los más importantes críticos de América hispánica, hayan sido no sólo críticos sino promotores de cultura, hayan estado intimamente asociados a editoriales, hayan fundado revistas.

No se crea que Paz no prevee esta objeción. En el mismo ensayo observa:

Se dice a menudo que la debilidad de nuestra crítica se debe al carácter marginal y dependiente de nuestras saciedades: es uno de los efectos del "subdesarrollo". Esta opinión es una de esas verdades a medias, peores que mentiras totales. El famoso "subdesarto1lo" no le impidió a Rodó escribir un buen ensayo crítico sabre Darío. (...)

Más acertada me parece la idea de ver en la dispersión de nuestra crítica una consecuencia de la falta de comunicación. América Latina no tiene un centro a la manera de París, Nueva York o Londres. ${ }^{15}$

Es indudable, pues, que Paz anticipa las objeciones, aunque podría observársele que si bien es cierto que el "subdesarrollo" no impidió a Rodó escribir sobre Darío, el subdesarrollo le impidió, sí, continuat su obra de crítico y ensayista con la total dedicación y exclusividad que sus:

${ }_{14}$ Cf. "Sobre la critica", in Carriente alterna, pp. "40-41.

15 Loc. cit., p. 43. 
contemporáneos de Europa y Estados Unidos disfrutaban ya entonces. Sus marmóreos párrafos fueron escritos en los intervalos que le dejaban abrumadoras actividades políticas, periodísticas y parlamentarias. Pero aún así, Paz reconoce explícitamente en el párrafo arriba citado, con una nitidez mayor que en la tirada de El arco y la liva, la dependencia que tiene la crítica con respecto a la sociedad a la que pertenece. La poesía puede crearse aún en el desierto. La crítica no. No es casual que sean los países mejor desarrollados los que tienen más abundante crítica. En Francia no es un secreto para nadie que las revistas literarias están directa o indirectamente subvencionadas por las grandes editoriales, y que estas mismas utilizan las obras de crítica para fomentar discretamente la creación de ese espacio intelectual que facilita la comprensión y difusión de la obra de arte. En América Latina, el desarrollo relativo de Buenos Aires en las últimas décadas del siglo XIX y en lo que va del veinte ha permitido, por ejemplo, la aparición de una crítica no sólo porteña sino ríoplatense, en la que habría que mencionar, además de los nombres invocados por Paz, los de Francisco Bauzá y Paul Groussac, Rubén Dario (que vivió tanto tiempo en la Argentina) y Leopoldo Lugones, Alberto Zum Felde y Martínez Estrada, Ernesto Sábato y David Viñas. Rodó, Borges y Cortázar no están tan solos realmente.

Pero la crítica no consiste solamente en la creación de un ámbito intelectual, por importante que éste sea. Es también la creación de un "doble" de la obra misma: doble que prolonga en el campo del discurso lo que la obra "dice" en el campo de la poesía. Paz lo sabe mejor que nadie ya que on sus análisis del poema en El arco y la lira, o en textos muy posteriores pero de la misma índole, examina precisamente la fun. ción del poema como "conductor de poesía". ${ }^{16}$ Por ser sólo un conductor, el poema no "contiene" sino que "trasmite" la poesía. La crítica hace lo mismo. Desde este punto de vista, el crítico no es sino un lector privilegiado, un lector que conduce a otros hacia el poema, que facilita la transmisión. Pero también cabe decir, a la inversa, que el lector es un crítico ya que al realizar su función, es decir: al leer, escuchar o repetir el poema, lo recrea. "Cada vez que el lector revive de veras el poema, accede a un estado que podemos llamar poético", dejó escrito Paz: ${ }^{\mathbf{1 7}}$ Con su habitual concisión, Borges había dicho (repitiendo a Schopenhauer) que cada hombre que lee una línea (un verso) de Shakespeare es Shakespeare. ${ }^{18}$

is Cf. "La línea central", in Puertas al campo, p. 102, donde dice: "Los poemas no contienen poesía: son buenos o malos conductores de poesía".

17 Cf. El arco y la lira, p. 26.

18 Cf. "Tlön, Uqbar, Orbis Tertius", in Ficciones (Buenos Aires, Sur, 1944), p. 26. Aquí la frase no' se identifica como de Schopenhauer, y se atribuye "a una 
En Octavio Paz la crítica no es sino una función complementaria de otra más central: la creación poética, y esta misma no es sino consecuencia de un apetito de ser y de trascender que tiene hondas raíces metafísicas. A medida que Paz iba descubriendo su poesía, iba descubriendo también la necesidad de explorar críticamente su mundo y de crear por si mismo ese espacio intelectual de cuya ausencia en nuestras letras tanto se ha quejado. Porque su obra poética no podía ser valorada en un medio como el mexicano, o el latinoamericano genera', de los años 40: medio que la polémica del "realismo" y de la literatura "social" y del arte "comprometido" habían reducido a la total esterilidad. Por eso, pues, Paz tuvo que realizar paralelamente a su obra poética, una obra crítica que le sirviera de apoyo y de irradiación. De su paso por el surrealismo francés a partir de 1945, de sus contactos con el marxismo y con el existencialismo, de su descubrimiento vertiginoso del Oriente en un viaje a la India y al Japón (1952), arranca todo un cuerpo crítico que tiene, a pesar de su superficial variedad, una firme coherencia interior. En una de sus dos obras básicas (El laberinto de la soledad), Octavio Paz logra explorar las raíces del ser mexicano y descubre en el horror sexual al otro la clave de su aislamiento y enajenación, y en la fiesta apunta Paz precisamente la única forma de comunión, de unión con el otro. En la otra obra básica (El arco y la lira), funda una concepción del poema que linda con la experiencia religiosa, que perpetúa el instante, que da sentido al ser, que realiza (también) la comunión. A partir de esos dos libros capitales y hasta cierto punto paralelos, Paz se dedica a continuar explorando las relaciones entre el lenguaje y la poesía, entre la religión y la poesía, entre el erotismo y la poesía, entre la sociedad y la poesía. Pero el signo central de esa exploración es el concepto de comunión. O mejor dicho: la conquista de la soledad, de la enajenación, por la comunión.

La soledad es el yo, una cárcel. Todo esfuerzo por lograr la comu_ nicación sólo puede culminat en la comunión, o fracasar totalmente. El esfuerzo puede asumir la forma de un poema o de una palabra sola; puede ser un gesto a una pintura, el canto o la música. Ha de ser, forzosamente, un lenguaje. Puede ser (como indica Lévi-Strauss) un len-

de las iglesias de Tlön"; pero en el mismo libro se incluye el cuento, "La forma de la espada", en que el relator cita la misma frase e indica la fuente (p. 150). También en "Nueva refutación del Tiempo" introduce Borges una variante estilística de la misma frase, pero sin indicar la fuente. Cf. Otras inquisiciones (Buenos Aires, Sur, 1952), p. 209. 
guaje que ocurre a través del hombre y sin que éste sea consciente de transmitirlo; un diálogo de mitos (otra tesis del antropólogo francés); o puede ser una revelación mágica, como sostenía Breton, o lo que sea. Lo esencial para Paz es la ruptura de la soledad para alcanzar la comunión. De ahí que el pensamiento crítico de Paz, después de haberse paseado por las culturas de Occidente y por las primitivas culturas americanas, se haya sentido fatalmente arrastrado hacia el pensamiento binario de Oriente.

Allí ha encontrado Paz la clave para disipar las contradicciones del pensamiento occidental; un sistema que permite la aceptación de la existencia del atro y la disolución del yo propio; una religión que instaura lo divino, y no un Dios único, como centro de sus creencias; una concepción del tiempo como algo cíclica y no lineal, lo que permite anulat las fantasías racionalistas del "progreso" y da un nuevo sentido a la empresa revolucionaria. Hasta la concepción del amor (central para este gran poeta erótico) encuentra en el pensamiento y en la experiencia estética de Oriente un apoyo solar. La comunión, la reconciliación de los contrarios, que Paz buscaba desde sus orígenes recibo una nueva definición a partir de la experiencia oriental.

\section{VI}

A diferencia de la de Paz, la obra crítica de Borges no se desarrolla armoniosa y progresivamente. Pasa por fases que se contradicen sutil o bruscamente, tiene hiatos, comparte abiertamente la paternidad de los textos con amanuenses, generalmente femeninos. Hay un período inicial que abarca tres volúmenes misceláneos -Inquisiciones (1925), El tamaño de mi esperanza (1926), El idioma de los argentinos (1928). Esos títulos reflejan al Borges joven: ultraísta algo claudicante y renegado, crítico polémico, barrocamente arbitrario. El Borges de la madurez ha condenado al olvido los tres volúmenes, aceptando la reedición posterior de un solo ensayo: el que da título al tercer volumen. El resto es parte de una prehistoria de su vida intelectual que interesa más a sus críticos que a él mismo. Una segunda etapa de su obra crítica consiste también de tres libros: Ia biografía tan singular de Evaristo Carriego (1930), obra que Borges escribió inicialmente en inglés y luego tradujo al castellano; mero pretexto, en realidad, para una reconstrucción muy personal del suburbio porteño, del mundo del tango y los cuchilleros suburbanos, y de las retóricas inscripciones de los carros de alquiler; un segundo libro explicitamente titulado Discusión (1932), en que ya se perfila mejor el Borges 
de la inquietud metafísica y la visión alucinatoria de la realidad; y un tercero, Historia de la eternidad (1936), que amplía y confirma la dirección metafísico_alucinatoria. En este último libro se incluye precisamente un texto, "El acercamiento a Almotásim", que asume la forma de reseña bibliográfica de una novela detectivesca publicada en Bombay pero que es, en realidad, uno de los primeros cuentos fantásticos del autor argentino.

A partir de 1936 y hasta llegar a 1951, hay un hiato aparente en la obra ensayística de Borges. Aunque continúa publicando ensayos en revistas y páginas literarias, y escribe algunos importantes prólogos (como el citado a la novela de Bioy Casares, o uno, admirable, a La Divina Comedia), Borges no publica ningún volumen original de crítica. En 1951 aparece Antiguas Literaturas germánicas (1951), que es en realidad un manual redactado por Cecilia Ingenieros sobre la base de un curso de Borges en la Facultad de Filosofía y Letras. La relativa insignificancia de este libro está certificada por el hecho de que en 1965, Borges lo reescribe con otro título y otra colaboradora, María Esther Vázquez. Tampoco será ésta la versión definitiva, a lo que parece. Nuevos estudios hechos en los Estados Unidos han convencido a Borges de la necesidad de redactar una tercera versión del elusivo tema.

El hiato señalado se explica, en parte, por razones biográficas. En 1938 Borges sufre un accidente (se golpea la cabeza contra una ventana entornada, al subir corriendo una escalera oscura). Las complicaciones de la herida, una septicemia, le cuestan casi la vida. Aunque se recupera, su capacidad de lectura y escritura quedan notablemente limitadas. A partir de esa fecha, Borges se concentra sobre todo en su obra de natrador fantástico, y los ensayos críticos que escribe no tienen por lo general otro objeto que elucidar oblicuamente sus problemas de narrador. Es la suya, entonces más que nunca, una crítica de practicante. Cuando en 1952, recoja en Otras inquisiciones los ensayos misceláneos de casi dos décadas se habrá de ver que el hiato es sólo en la publicación de libros pero que su pensamiento ensayístico, paralelo al ejercicio de la creación narrativa, ha tomado cuerpo considerable. Otras inquissiciones es, sin lugar a dudas, su obra crítica más importante.

Todo lo que ha publicado Borges como crítico a partir de ese volumen es relativamente insignificante. Hay un estudio, breve, sobre $E l$ "Martín Fierro", dictado a Margarita Guerrero (1953); hay un importante prólogo a una antología de La poesía gucuchesca (1955), escrito en colaboración con Adolfo Bioy Casares y en que se recoge la sustancia de artículos ya publicados por Borges en Discursión y en otros lugares; hay un Leopaldo Lugones (1955), que también firma Betina Edelberg; 
y hay sendos manuales de Introducción a la literatura inglesa (1965, con María Esther Vázquez, otra vez) y de Introducción a la literatura norteamericana (1967, con Esther Zamborain de Torres) que reproducen notas tomadas por secretarias durante sus clases en la Facultad de Filosofía y Letras. Los últimos años de Borges lo han visto volver con empeño a la poesía rimada, más fácil de componer en el ámbito de la sombra; renovar el poema en prosa, el apólogo, la parábola, géneros todos susceptibles de ser manejados con brevedad, concentración, intensidad. También lo han visto rescatar el relato conciso de escritores realistas como Maupassant o Kipling, dos lecturas de la juventud. Pero su ceguera casi total le ha impedido desde 1956 continuar su obra ensayística en el altísimo nivel que la habían situado los tres volúmenes últimos. Es en Discusión, en Historia de la eternidad y en Otras inquisiciones donde descansa por ahora la fama de Borges como crítico y ensayista.

Una preocupación central, casi diría una obsesión, enlaza fuertemente los tres volúmenes: el tema del Tiempo. Lo que es una serie, en apariencia inconexa, de referencias en varios artículos del primer libro, se convierte en el trabajo que da título al segundo volumen, y reaparece dentro del mismo libro en, por lo menos, dos ensayos más: "La doctrina de los ciclos", "El tiempo circular". En el tercer volumen se concentra en el ensayo más largo, esa "Nueva refutación del Tiempo", que recoge todo el material anterior, lo organiza en dos series de argumentos, y concluye por llevarlo a una doble conclusión contradictoria. El ensayo había sido anticipado en una plaquette de 1947 que circuló exclusivamente en forma no comercial. Al ser.incorporado a su obra crítica más importante, Borges contribuye a situarlo en el contexto más central y favorable. Pero el libro entero resuena con el tema del tiempo, de la negación de la realidad, del rechazo de la personalidad individual.

En "Nueva refutación del Tiempo" Borges defiende una concepción idealista de la realidad que ya había explorado en un par de artículos de las primeras Inquisiciones -artículos escritos a la vera de conversacianes con Macedonio Fernández- pero que sólo ahora se organizan en una unidad más compleja. Siguiendo algunos textos (siempre los mismos) de David Hume, el obispo Berkeley y Schopenhauer, pero enriqueciéndolos y hasta deformándolos con su propia intuición del Tiempo y con una experiencia (casi alucinatoria) que tuvo en 1928, el escritor argentino niega allí no sólo el Tiempo sino también el espacio, disuelve en nada el mundo exterior, anula la identidad individual. No es ésta la ocasión de examinar en detalle el sentido preciso de estas negaciones. 
Lo que me interesa apuntar ahora son las consecuencias críticas y poéticas de esta visión del munda. ${ }^{19}$

Al negar la identidad individual, Borges anula precisamente la posibilidad de la comunión que es tan importante para Octavio Paz. Porque aquél disuelve el yo no para lograr (como los orientales) la conciliación de los contrarios, la unión íntima con el otro, sino para eliminar de una vez el yo y el otro. Nadie es alguien, dice y repite su obra entera. Esta negación, al ser trasladada a la literatura, destruye el concepto de creación. Cuando Borges cita a Schopenhauer en algunos de sus cuentos para decir que "todos los hombres que repiten una línea de Shakespeare son Shakespeare", no es para hacer compartir a sus lectores la gloria del maestro isabelino, sino para aniquilar las pretensiones de paternidad literaria que aquél pudiera tener. Nadie es alguien, Shakespeare es todos (como sospechó románticamente De Quincey); Shakespeare es nadie, como ahora insinúa Borges.

En uno de los ensayos de Otras Inquisiciones ("La flor de Coleridge" se llama), Borges sostiene con apoyo en sendas citas de Paul Valéry, Emerson y Shellcy, que la literatura universal parece haber sido escrita por un solo autor, el Espíritu. ${ }^{20}$ Esta teoría, de un panteísmo literario un si es no es romántico, permite a Borges disolver la noción de un autor original en la noción, más impersonal, de la literatura. Nadie (otra vez) es alguien. Lo que pasa es que las consecuencias últimas de esta teoría van más allá de la mera negación (al fin y al cabo idiosincrática) de la personalidad individual del autor. Una estética de la lectura, en vez de una estética de la escritura, está implícita en esa negación. Borges invierte aquí los términos habituales del debate literario: en vez de apoyar todo el énfasis en la creación original de la obra lo hace en la creación, posterior y siempre renovada, del lector. Las consecuencias de esta inversión son alucinantes.

Esta estética de la lectura (cuyos laberínticos caminos na podemos explotar aquí) aparece insinuada ya desde sus primeros y cancelados libros. ${ }^{21}$ Pero donde está más cabalmente expuesta es en uno de sus más

19 En varios lugares me he ocupado, desde 1947 por lo menos, de la visión borgiana del mundo. Una exposición bastante completa puede encontrarse en mi ensayo, "Borges: Teoría y práctica", in Numero, No. 27, Montevideo, diciembre, 1955, pp. 124-157. También en "Borges, essayiste", in L'Herne, París, 1964, pp. 343-351. Una nueva versión del mismo tema se puede leer en mi Borgès par luimême (París, Editions du Seuil, 1970), pp. 75-85, especialmente.

20 Cf. "La flor de Coleridge", in Otras Inquisiciones, p. 17.

21 Sobre la estética de Borges, además de los textos citados en la nota 19, me remito a un extenso trabajo mío, "Borges: the Reader as Writer". Aqui resumo algunos de los puntos allí expuestos en Prose for Borges, en Tri-Quaterly (Northwestern University, Evanston, Illinois, No. 25, Fall 1972), pp. 102-143. 
famosos cuentos, "Pierre Menard, autor del Quijote", precisamente el primero que escribe al recuperarse del accidente de 1938. Como se sabe, el cuento pretende resumir la vida y obra de un apócrifo escritor francés post-simbolista que se ha propuesto reescribir el Quijote pero sin cambiar una sílaba, una coma, una errata. Al final de mucha especulación y ensayos, consigue reproducir una frase sobre la historia, madre de la verdad, que figura literalmente en la obra original. Pero el concepto de Cervantes y el de Menard (apunta Borges) son distintos. Cervantes, ingenio lego, hombre del siglo xvIr, puede creer que la Historia es la madre de la verdad: Menard, contemporáneo de William James, jamás Por otra parte (continúa Borges) hasta el estilo es distinto: en Cervantes se nota el escritor que usa la lengua de su tiempo; en Menard, el esfuerzo arcaizante del extranjero. La conclusión del cuento desnuda la intención de Borges:

Menard (acaso sin quererlo) ha enriquecido mediante una técnica nueva el arte detenido y rudimentario de la lectura: la técnica del anacronismo deliberado y de las atribuciones erróneas. Esa técnica de aplicación infinita nos insta a recorrer la Odisea como si fuera posterior a la Eneida... (...) Esa técnica puebla de aventura los libros más calmosos. Atribuir a Louis Ferdinand Cèline o a James Joyce la Imitación de Cristo ino es suficiente renovación de esos tenues avisos espirituales ? ${ }^{22}$

Cuatro años antes, al prologar en 1935 la primera edición de su Historia Universal de la Infamia, Borges había advertido:

En cuanto a los ejemplos de magia que cierran el volumen, no tengo otro derecho sobre ellos que los de traductor y lector. A veces creo que los buenos lectores son cisnes aún más tenebrosos y singulares que los buenos autores. Nadie me negará que las piezas atribuidas por Valéry a su pluscuamperfecto Edmond Teste valen nctoriamente menos que las de su esposa y amigos. . . Leer, por lo pronto, es una actividad posterior a la de escribir: más resignada, más civil, más intelectual. ${ }^{23}$

En el mismo prólogo, y en un "Indice de las fuentes", al final, Borges apunta los libros de los que ha tomado esas historias "reales"

22 Cf. "Pierre Menard, autor del Quijote", in Ficcianes, pp. 62-63.

23 Cf. Historia Universal de la Infamia (Buenos Aires, Colección Megáfono, $1935)$, p. 6. 
de piratas, negreros, impostores, gangsters y asesinos. Lo que no dice allí es que las vidas que resume, con tanta arbitrariedad como talento, son casi tan imaginarias como las de Marcel Schwob que le sirvieron de remoto modelo. Tampoco dice que uno de los personajes (el enmascarado tintorero Hákim de Merv) es casi totalmente inventado. ${ }^{24}$ A esta altura de la discusión, podría observar Borges, es superfluo indicar si una obra "es original" o está "copiada" de otra fuente. Toda historia, todo texto, es definitivamente original porque el acto de creación no está en la escritura sino en la lectura.

La crítica francesa, sobre todo a partir de Gerard Genette, ha tomado esta idea de Borges y la ha desarrollado considerablemente. El ensayo de Genette, originalmente publicado en 1964, se titula, "La littèrature selon Borgès", y sostiene lo siguiente:

La genèse d'une oeuvre dans le temps de l'histoire et dans la vie d'un auteur, est le moment le plus contingent et le plus insignifiant de sa durée. (...) Le temps des oeuvres n'est pas le temps défini de l'écriture, mais le temps indéfini de la lecture et de la mémoire. Le sens des livres est devant eux et non derrière, il est en nous: un livre n'est pas un sens tout fait, une révelation que nous avons à subir, c'est une réserve de formes que attendent leur sens, c'est "l'imminence d'une révelation qui ne se produit pas", et que chacun doit produire pour lui-même. ${ }^{25}$

Esta noción central de Borges - que Genette subraya en su estudio y cuyas raíces estéticas y psicológicas no puedo estudiar aquí ha sido una de las más fecundas para la crítica actual. Al centralizar el enfoque en el acto de leer, Borges ha liberado a la literatura del prejuicio biográfico, ha soslayado delicadamente la iconografía (válida, por lo menos, desde Longinos) de una lujosa galería de Grandes Autores, ha devuelto al lenguaje (medio que es de nadie porque es de todos) su pri-

24 Jorge Luis Borges: "An Autobiographical Essay", in The Aheph and Other Stonies, 1933-1969 (New York, E. P. Dutton, 1970), p. 239. Al referirse alli a la Historia Universal de la Infamia, apunta Borges: "I did not want to repeat what Marcel Schwob had done in his Imaginary Lives. He had invented biographies of real men about whom little or nothing is recorded. I, instead, read up on the lives of known persons and then deliberately varied and distorted them according to my own whims." El reconocimiento algo tardio de sus variaciones y distorsiones no incluye, sin embargo, la admisión de que "El tintorero enmascarado Hákim de Nerv" es casi totalmente una fabricación original.

25 Cf. "La littétature selon Borges", in L'Herne, pp. 323-327. El artículo está recogido, en una versión algo corregida, en el libro de Genette: Figures (París, Editions du Seuil, 1966), pp. 123-132. El título del attículo ha sido modificado; ahora se llama, "L'utopie littéraire". Cito por esta versión, p. 132. 
macía. A partir de esta noción del lector como autor, torla una estética nueva puede edificarse. Por el camino de la lectura, y en la actividad individual del incesante diálogo de textos que la lectura presupone, Borges ha encontrado una salida para sus múltiples negaciones, una respuesta a su total aislamiento, un ámbito para la comunión. Ya que el verdadero creador de un texto no es el autor sino el lector, todo lector es todos los autores. Todos somos uno.

En esta intuición, que permite fundar una estética de la lectura, se resumen más de treinta años de especulaciones parciales de este meditador deliberadamente fragmentario que es Borges. Que el reconocimiento de esta estética haya debido esperar a la crítica francesa más reciente para ser discutida y examinada con la necesaria seriedad, es una prueba más de la ausencia de un espacio intelectual en la cultura latinoamericana de que hablaba Paz en las páginas citadas un poco más arriba. Aunque no han faltado en el Río de la Plata quienes leyeron a Borges en profundidad, y hasta intentaron codificar en libros y estudios sus intuiciones críticas, la mayoría de los lectores latinoamericanos sólo vieron en sus ensayos (cuando algo vieron) la fantasía de un escritor que, como no reconoce límites entre los géneros, transporta a la crítica los métodos de la ficción y a la ficción los de la crítica. En Francia (la patria de Pierre Menard, no se olvide) Borges fue leído más imaginativamente.

El malentendido es muy revelador. ${ }^{26}$

\section{VII}

Podemos. volver ahora a las afirmaciones de Octavio Paz sobre la ausencia entre nosotros de una crítica como espacio intelectual; ámbito de ideas, medio en el que una obra adquiere significación y una literatura llega a definirse realmente. El caso de Borges es ejemplar de esa ausencia. Sus ideas críticas estaban ahí, a la vista de todos. En sus cuentos y en sus

26 Emir Rodríguez Monegal, El juicio de las parricidas (Buenos Aires, Deucalión, 1956), pp. 55-79, en particular. Se discuten allí, sobre todo, las falacias de la crítica argentina frente a Jorge Luis Borges; falacias que todavía siguen repitiéndose como lo demuestra el lamentabilísimo libro que acaba de publicar Blas Matamoros: Jorge Luis Borgils, o El juego trascendente (Buenos Aires, A. Peña Lillo editor, 1971). También se indican en mi libro de 1956 los mejores estudios argentinos publicados hasta entonces. Faltan, naturalmente, el libro de Ana Maria Barrenechea: La expresión de la irrealidad en la obra die Jorge Luis Borges (México, El Colegio de México, 1957), y el de Jaime Alazraki: La prosa narativa de' Jorge Luis Borges (Madrid, Editotial Gredos, 1968). Estos dos estudios son los únicos que han pretendido estudiar en la Argentina la obra de Borges con alguna seriedad. No me parece casual que ambos se hayan publicado en el extranjerto. El tema se prestaría a una investigación detallada. 
poemas, pero sobre todo en sus ensayos, una estética de la lectura quedaba insinuada. Pero cuántos de los que podían aprender en Borges se tomaron realmente el trabajo de leerlo; cuántos de los que sí lo leyeron, se propusieron discutirlo seriamente; cuántos (de verdad) lo hicieron. Ni siquiera Paz, lector tan omnívoro como calificado, parece haber leído Otras inquisiciones en la hora de su primera sálida. La estética de Borges, conocida y glosada por muy pacas en el Río de la Plata entonces, debió esperar unos doce años por lo menos desde la publicación de aquel libro en 1952 hasta la aparición del ensayo de Genette on 1964, para encontrar una audiencia a escala universal. Aún hoy, casi veinte años después, sigue casi ignorada en una América Latina en donde se continúa prestando toda atención a sus deplorables declaraciones políticas mientras se descuida la práctica de sus textos capitales. Tanta ignorancia no puede ser involuntaria.

Creo que no hay mejor ilustración de esa ausencia de un espacio intelectual que el caso de Borges. Pero también creo que Octavio Paz exagera en el afán de hacer más nítido su argumento. Como ardiente crítico practicante que es, Paz tione la impaciencia del profeta. Le duele, le hiere, le ofende incesantemente la ausencia del diálogo intelectual en la Anérica Latina. Todos hablan, nadie escucha, podria haber dicho. O lo que es, tal vez, peor: nadie habla, nadie escucha. Las consignas, los slogans, las mafias, funcionan a todos los niveles e impregnan todos las grupos. Todos esperamos (como prisioneros en la caverna platónica) que la luz nos llegue de otro lado: de Europa o los Estados Unidos. de la Unión Soviética o de China, de Cuba o de Chile. Nunca de nosotros mismos. Quiero decir: de nuestra propia lectura. Todos juzgan sin leer; todos se creen autorizados a juzgar sin leer.

No digo que Paz formule así la situación. Sin embargo, aquí creo encontrar la sustancia de su crítica a la mediocridad del ambiente intelectual latinoamericano. Crítica que, por otros caminos y con otra fraseología, entronca con lo que Borges ha dicho en tantos lados, y, sobre todo, en la conferencia, "El escritor argentino y la tradición", ya citada.

Insisto: hay una exageración en el tono de Paz; exageración que él no puede evitar por razones de argumentación, pero que sus lectores sí debemos rectificar. Porque la existencia de una obra crítica como la de Borges, que Paz ha examinado pero que no conoce en detalle; la existencia de una obra como la de Alfonso Reyes, que tanto Paz como Borges han estudiado bien y admiran profundamente; pero, sobre todo, la existencia de una obra como la de Octavio Paz, son la mejor prueba de que el diálogo intelectual puede existir en América Latina. Las premisas fundamentales han sido ya echadas por estos y los otros críticos que se han mencionado 
en este trabajo, y por muchos más que por razones obvias no puedo mencionar aquí.

Y diría más: el diálogo se ha iniciado hace un tiempo ya. Son muchos los que han aprendido en Reyes y en aquel su amigo, don Pedro Hentíquez Ureña, muchos los que han aprendido en Mariátegui y en Martínez Estrada, en Lezama Lima y en Borges, en Octavio Paz, a leer y a escribir, a pensar e inventar, a soñar un poco más críticamente a nuestra América. No es posible abrir hoy una revista literaria, una página cultural cualquiera, una sección bibliográfica, sin que encontremos aquí o allí algún reflejo de la obra de estos maestros a quienes cabe reconocer como la base colectiva de un pensamiento crítico hispanoamericano contemporáneo. Ellos aquí, y un Antonio Cándido en Brasil, han sabido levantar los fundamentos del diálogo crítico a una altura que no desmerece la alcanzada hoy en el resto del mundo.

Es verdad, sí, que estamos sumergidos en la mediocridad cultural del subdesarrcllo y que tencmos que enseñar a leer los primeros palotes antes de enseñar a leer a Borges. Es verdad que las grandes empresas capitalistas, nacionales e internacionales, analfabetizan con los medios masivos de comunicación a los pocos alfabetos que todavía producen nuestras instituciones de enseñanza. Es verdad que estamos sometidos a la emisión incesante de slogans políticos fabricados por comisarios de regímenes que generosamente se autocalifican de revolucionarios. Es verdad que la censura, explícita o implícita, de los guardianes de la moral y las buenas costumbres nos quieren imponer sobre qué escribir y (especialmente) sobre qué no escribir. Todo eso es cierto, sí, y nuestra América tiene que enfrentar tadas esas realidades antes de poder crear ese espacio intelectual del diálogo que propone Paz.

Pero no menos cierto es que algunos escritores y algunos lectores (la distancia entre unos y otros la ha borrado ya Borges), no han cejado ni cejarán jamás en su empresa de echar las bases de diálogo. Gracias a ellos, el Espíriti (como suponía Valéry) continuará escribiendo esa obra que es de todos y que es de ninguno: la Obra que cada lectura, cada escritura, renueva incesantemente. 
